\title{
The cost of lost productivity due to premature mortality associated with COVID-19: a Pan-European study
}

\author{
Paul Hanly $^{1}{ }^{1} \cdot$ Michelle Ahern $^{1} \cdot$ Linda Sharp ${ }^{2} \cdot$ Diana Ursul $^{1} \cdot$ Gerard Loughnane $^{1}$
}

Received: 6 January 2021 / Accepted: 8 July 2021 / Published online: 21 August 2021

(c) The Author(s), under exclusive licence to Springer-Verlag GmbH Germany, part of Springer Nature 2021, corrected publication 2021

\begin{abstract}
Background Economic cost estimates have the potential to provide a valuable alternative perspective on the COVID-19 burden. We estimate the premature mortality productivity costs associated with COVID-19 across Europe.

Methods We calculated excess deaths between the date the cumulative total of COVID-19 deaths reached 10 in a country to 15th May 2020 for nine countries (Belgium, France, Germany, Italy, The Netherlands, Portugal, Spain, Sweden and Switzerland). Gender- and age-specific excess deaths and Years of Potential Productive Life Lost (YPPLL) between 30 and 74 years were calculated and converted into premature mortality productivity costs $€ 2020$ for paid and unpaid work using the Human Capital and the Proxy Good Approaches. Costs were discounted at 3.5\%.

Results Total estimated excess deaths across the nine countries were 18,614 (77\% in men) and YPPLL were 134,190 $(77 \%$ male). Total paid premature mortality costs were $€ 1.07$ billion ( $87 \%$ male) with Spain ( $€ 0.35$ billion, $33.0 \%$ of total), Italy ( $€$.22 billion; $20.6 \%)$ and The Netherlands ( $€ 0.19$ billion; $17.5 \%)$ ranking highest. Total paid and unpaid premature mortality costs were $€ 2.89$ billion (77\% male). Premature mortality costs per death ranged between $€ 40,382$ (France) and $€ 350,325$ (Switzerland). Spain experienced the highest premature mortality cost as a proportion of Gross Domestic Product $(0.11 \%)$. Conclusion Even in the initial period of the pandemic in Europe, COVID-19-related premature mortality costs were significant across Europe. We provide policy makers and researchers with a valuable alternative perspective on the burden of the virus and highlight potential economic savings that may be accrued by applying timely public health measures.
\end{abstract}

Keywords COVID-19 · Europe · Premature mortality · Productivity loss · Economic burden · Human capital

JEL Codes $\mathrm{H} 5 \cdot \mathrm{I} 1 \cdot \mathrm{I} 3 \cdot \mathrm{J} 1$

Paul Hanly

paul.hanly@ncirl.ie

Michelle Ahern

Michelle.ahern@ncirl.ie

Linda Sharp

linda.sharp@ncl.ac.uk

Diana Ursul

ursul.diana@gmail.com

Gerard Loughnane

Gerard.Loughnane@ncirl.ie

1 National College of Ireland, Mayor Street, Dublin 1, Ireland

2 Newcastle University, Newcastle upon Tyne, UK

\section{Introduction}

The COVID-19 pandemic has spread rapidly across the globe affecting individuals, populations and the wider macroeconomy [1]. Public health measures including lockdowns, physical distancing, closure of schools and nonessential business, and travel restrictions are struggling to mitigate the spread of disease [1]. The global number of infections and deaths continues to rise and the economy looks set to enter one of the deepest recessions for $8 \mathrm{dec}-$ ades [2, 3]. These human, health and economic tolls are all intertwined and offer alternative perspectives on a growing global burden [2].

Europe accounted for one in five COVID-19 infections globally and two in five COVID-19-related deaths as of 1st June 2020 [2]. Older people with comorbidities are most at risk of death with those aged over 70 accounting for $85 \%$ 
of all COVID-19-related deaths across Europe [2]. However, younger people with no known comorbidities can also experience rapid decline and death. While numbers of deaths from COVID-19 are useful for assessing the population disease health burden, these have some well recognised limitations, including differences in definitions and methods of counting and disregard of deaths that are indirectly due to the virus [4]. Policymakers require a range of measures to appropriately assess the societal burden and make efficient resources allocation decisions; these include economic metrics.

Economic cost estimates have the potential to provide a valuable alternative perspective on the burden of disease. They can facilitate evaluation of the costs and potential future benefits to society of past and future policy interventions (e.g. those aimed at 'flattening the curve' of the COVID-19 pandemic). The economic costs of a specific condition can be compared with those for other health problems to inform efficient resource allocation decisions such as rationing and population restrictions including lockdowns $[5,6]$.

Estimated direct healthcare costs of $\$ 3045$ per COVID19 case in the US have been reported [7]. However, indirect costs can account for a significant proportion of the total economic cost of diseases and include the monetary value of productivity loss arising from absence from paid work and other unpaid activities (e.g. caring) due to morbidity and mortality [8]. Premature mortality is a major contributor of these costs and can impact on the potential for future economic growth [9].

We estimate, for the first time, the premature mortality costs associated with COVID-19-related excess mortality across nine European countries during the initial months of the outbreak. We employ a societal perspective using the human capital approach (HCA) and the proxy good approach (PGA). The results will support attempts to measure the efficiency of public health containment measures so far and inform future policy initiatives that aim to minimise the economic burden, in addition to the population health burden, of the disease.

\section{Methods}

\section{General approach}

We focus on excess premature mortality during the initial phase of the COVID-19 outbreak up until 15th May 2020. We define premature mortality as excess mortality in the population over our study period, that is deaths from all causes in the study period, compared to average deaths from all causes over the same period for the previous 5 years for each country (baseline mortality) (except for France, see below); excess mortality is considered the most appropriate epidemiological measure of the mortality impact of a pandemic, as it captures deaths directly due to infection, and deaths indirectly due to the pandemic, for example, because of delayed access to healthcare [10]. Countries selected included: Belgium, France, Germany, Italy, The Netherlands, Portugal, Spain, Sweden and Switzerland, where data were available in sufficient detail by gender and by age. We calculated years of potential productive life lost (YPPLL) for males and females aged between 30 and 74 .

We applied the HCA to value YPPLL for paid work of employed individuals [11]. Unpaid work of employed and non-employed individuals was valued by the PGA [8]. Leisure time is not valued. Productivity costs were expressed in 2020 Euros.

\section{Data sources}

\section{Excess mortality data}

Mortality data for our selected countries (except Germany) from 2015 to the 20th week of 2020 (week ending 15th May) were sourced from an exceptional temporary database collection from Eurostat [12]. Mortality data were aggregated by gender and by age ( 5 year age bands from 0 to $90+$ years), on a weekly basis. Baseline (usual pre-pandemic) mortality was based on data for 2015-2019, except for France where 2018 and 2019 were taken as the baseline due to data unavailability. Mortality data for Germany from 2015, reported on a weekly basis, were sourced from the Federal Statistical Office [13], aggregated by age only $(0-30,30-50,50-55$, and 5-year age bands up to 95).

\section{Economic data}

Paid work We sourced average gross annual earnings by gender, age group (30-39, 40-49, 50-59, 60+) and country [14]. Wages were inflated to 2020 values using the Harmonized Index of Consumer Price and future wage growth was approximated by per country Gross Domestic Product (GDP) growth between 2000 and 2018 [15]. We sourced unemployment rates and labour force participation rates by gender and age $(<30,30-39,40-49,50-59,60-64,65-74)$ [16].

Unpaid work "Time Use Survey 2010" was used for population level estimates of unpaid work [17]. Unpaid production was categorised by: (1) household work including food preparation and house cleaning for example; (2) family care including childcare and informal help to household and non-household members and (3) organisational work (e.g. volunteer work). Unpaid work time was stratified by country and gender. Time spent on non-paid activity by those in paid work and those not in paid work was differentiated. 
Time allocated to household work was valued at the rate of country-specific 'Elementary Occupation' wages which included occupations such as cleaners and helpers and food preparation assistants. Family care and organisational work was valued at the rate of 'Services and Sales Workers Personal' which included, amongst others, services workers and personal care workers [18].

\section{Theoretical background}

There are numerous avenues by which an infectious disease influences the economy. Population health in terms of increased life expectancy and reduced mortality is positively associated with economic welfare and growth, and hence negative health shocks invariably impact the economy over time. Following the theory of human capital [19], we applied the Human Capital Approach (HCA) [11] to value the years of potential productive life lost following a COVID19-related premature death for employed individuals. The model views health as a durable capital stock that produces an output of healthy time [11]. In terms of application, the HCA involves the adoption of a societal, or welfare-based, perspective to measure the potential stream of output that could have been produced over the course of a lifetime. This approach assumes a loss of productivity at work and at home following a reduction in health status or death. The total value of production lost is set equal to the present value of all lost future earnings of the individual up to the age of retirement [8]. Non-paid work of the employed and nonemployed was costed by the PGA. The PGA assumes that time allocated to non-market activities can be valued at its shadow price or a market wage equivalent. The PGA can be used to value time spent on household tasks and caring not remunerated by the market. A market equivalent wage for a close substitute activity is used to value the unpaid productivity lost based on the cost of hiring a paid worker to perform the task [8].

\section{Estimation approach}

The first step in the analysis was to calculate excess mortality. Since the pandemic took hold at different times in each country, the study period varied; the starting date was the week in which the cumulative total of COVID-19-related deaths reached 10 in that country (refer to Supplementary Table 1); the end date was 1st May 2020 (for France and Italy) and 15th May 2020 (for Belgium, Germany, The Netherlands, Spain, Sweden and Switzerland). For each country, gender and age group, excess deaths were calculated by subtracting the number of deaths in the study period by the annual average over the same time period in 2015-2019 (or 2018-2019 for France).
To be able to synthesise mortality data and economic data with differing age classes, we disaggregated excess deaths into mortality by year of age. For example, if there were 100 deaths in the age class 55-59, this was disaggregated into a uniform distribution of 20 deaths at age 55, 20 at age 56, etc. We further performed a linear interpolation between mortality counts at the midpoint of each age class, essentially smoothing between the different mortality counts of each age class. Inspection of excess mortality by age and gender revealed no notable excess mortality under 30 in any country, therefore, we restricted consideration to age 30 and older. In addition, any negative values in excess mortality for a particular age above 30 were set at zero, under the assumption that COVID-19 did not have any beneficial effects in terms of mortality in the study period.

For each excess death, we estimated YPPLL relative to an upper age limit of 75 . To estimate premature mortality costs, for each excess death, we multiplied YPPLL by country- gender- and age-adjusted market wages adjusting for country-specific annual GDP growth, and discounting future earnings by $3.5 \%$ annually [20]. We accounted for the effect of hypothetical potential future age progression of individuals had they lived—on wage, labour force participation and unemployment probabilities. Estimates were summed to produce total premature mortality costs, by country, sex and age group. Each YPPLL was also apportioned a time allocated to non-paid work and estimated time spent on each unpaid non-market activity was multiplied by the relevant (substitute) market wage, aggregated to an annual cost and summed. Costs per death were calculated as total premature mortality costs (by cost type) divided by the number of excess deaths per country, and total paid premature mortality costs were compared as a percentage of Quarter 2 2019 GDP by country.

\section{Results}

\section{Excess deaths and years of potential productive life lost (YPPLL) by country and gender}

The total estimated excess deaths between the ages of 30 and 74 up to 15th May 2020 across the nine European countries was 18,614 (Table 1). Male deaths represented $76.7 \%$ of the total. Spain recorded the highest number of deaths (7573, with males accounting for $73.1 \%$ ) followed by Italy (4201 deaths, males $90.0 \%$ ) and France (3687, males 67.3\%). No excess deaths were estimated for Germany (therefore, German figures are not reported subsequently).

Similar rankings were produced for YPPLL which totalled 134,190 (males 76.7\%). The crude excess mortality rate per 100,000 of the population between 30 and 74 was highest in Spain (28.2/100,000), followed by Belgium (16.0) 
Table 1 Number of excess deaths and years of potential productive life lost (30-74) by country and gender following initial country outbreak to 1st June 2020

\begin{tabular}{|c|c|c|c|c|c|c|c|c|c|c|}
\hline \multirow[t]{2}{*}{ Region/country } & \multicolumn{4}{|c|}{ Excess deaths } & \multicolumn{4}{|l|}{ YPPLL } & \multirow[b]{2}{*}{$\begin{array}{l}\text { Death rate per } \\
100,000\end{array}$} & \multirow[b]{2}{*}{ Rank } \\
\hline & Males & Females & Total & Rank & Males & Females & Total & Rank & & \\
\hline Belgium & 780 & 258 & 1037 & 5 & 5275 & 1447 & 6721 & 5 & $16 \cdot 0$ & 2 \\
\hline France & 2482 & 1205 & 3687 & 3 & 15,315 & 8988 & 24,303 & 3 & 9.9 & 5 \\
\hline Germany $^{\mathrm{a}}$ & - & - & - & - & - & - & - & - & - & - \\
\hline Italy & 3762 & 439 & 4201 & 2 & 24,452 & 1681 & 26,133 & 2 & $11 \cdot 6$ & 4 \\
\hline The Netherlands & 1099 & 249 & 1348 & 4 & 8594 & 1049 & 9643 & 4 & $14 \cdot 6$ & 3 \\
\hline Portugal & 188 & 83 & 271 & 7 & 1531 & 772 & 2303 & 7 & $4 \cdot 4$ & 7 \\
\hline Spain & 5536 & 2037 & 7573 & 1 & 44,159 & 16,947 & 61,106 & 1 & $28 \cdot 2$ & 1 \\
\hline Sweden & 377 & 26 & 402 & 6 & 3146 & 43 & 3189 & 6 & $7 \cdot 1$ & 6 \\
\hline Switzerland & 56 & 39 & 95 & 8 & 423 & 370 & 793 & 8 & $1 \cdot 9$ & 8 \\
\hline $\begin{array}{l}\text { Total (for } 8 \text { Euro- } \\
\text { pean countries) }\end{array}$ & 14,280 & 4335 & 18,614 & & 102,894 & 31,296 & 134,190 & & & \\
\hline
\end{tabular}

The starting point for each country varied and was defined as the week in which the cumulative total of COVID-19-related deaths reached 10 in that country

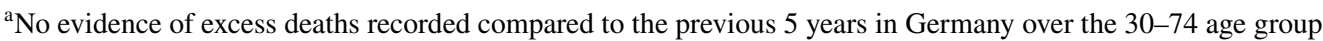

and The Netherlands (14.6). The lowest was Switzerland $(1.9 / 100,000)$.

\section{Premature mortality costs by country and gender}

Table 2 reports total paid COVID-19 premature mortality costs of $€ 1.07$ billion. Deaths in males accounted for $87.0 \%$ of the total. By country, Spain ranked highest with a cost of $€ 0.35$ billion (33.0\% of the total), followed by Italy ( $€ 0.22$ billion; 20.6\%) and The Netherlands ( $€ 0.19$ billion; 17.5\%).

Unpaid production lost due to premature mortality totalled $€ 0.23$ billion for employed people. Unpaid production lost amongst non-employed people amounted to $€ 1.59$ billion, or 1.5 times the size of paid production. France and Belgium in particular had an unpaid non-employed burden far in excess of their employed paid work burden (3.0 times and 2.5 larger).

Total paid and unpaid premature mortality loss was $€ 2.89$ billion of which males accounted for $77.3 \%$. Paid production costs accounted for $37.0 \%$ of the total; the proportion was lowest in France (23.6\%) and highest in Portugal (66.0\%).

\section{Premature mortality costs by country, gender and age}

Premature mortality costs by age for males across Europe tended to peak in the 55-64 age group (7 out of 8 countries; these analyses could not be conducted for Germany) (Fig. 1). This age group accounted for between 37.5\% (Belgium) and $66.5 \%$ (Portugal) of the total male premature mortality costs across these countries. For females, the picture was less consistent with a range of age groups generating the highest costs across countries.

\section{Premature mortality costs per death by country and gender}

The mean premature mortality cost per death for paid work for employed individuals ranged between $€ 40,382$ in France and $€ 350,325$ in Switzerland (Table 3). The mean cost in males was higher than in females; this ranged from 1.03 times higher in France to 13.84 times higher in Sweden (Supplementary Table 2).

The average unpaid productivity cost per premature death amongst non-employed people ranged between $€ 19,584$ in Portugal to $€ 153,869$ in Switzerland; these costs were between 0.35 (Portugal) and 3.0 (France) times the size of equivalent costs for paid lost productivity. For non-employed unpaid costs, female costs were larger than male costs for six of the eight countries.

\section{Premature mortality costs compared to economic output (GDP)}

Spain experienced the highest burden from premature mortality due to COVID- 19 at $0.11 \%$ of their Quarter 2 GDP for 2019, followed by The Netherlands $(0.09 \%)$ and Italy/Sweden (0.05\%) (Fig. 2). The lowest burden was recorded for Switzerland $(0.02 \%)$. 


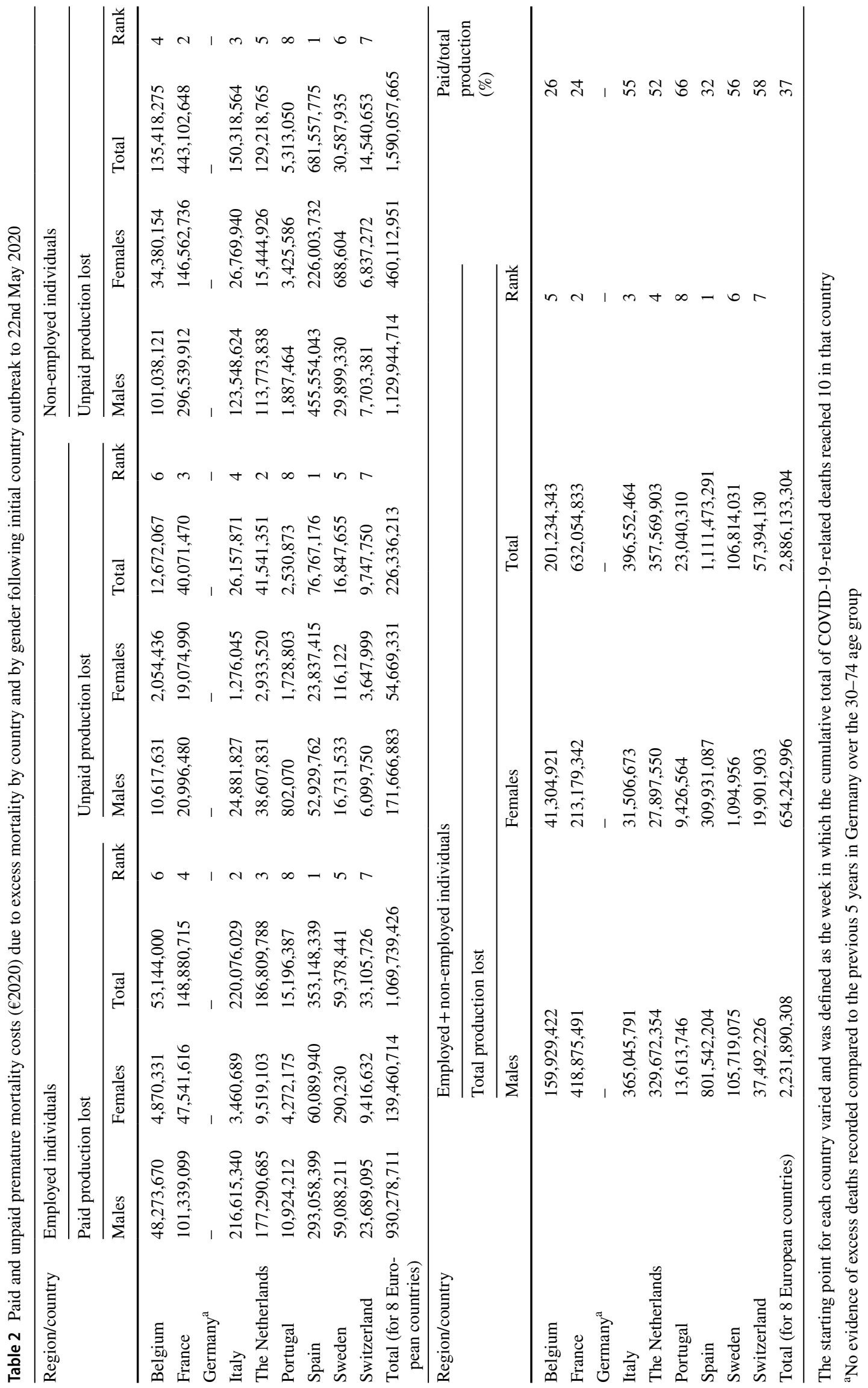



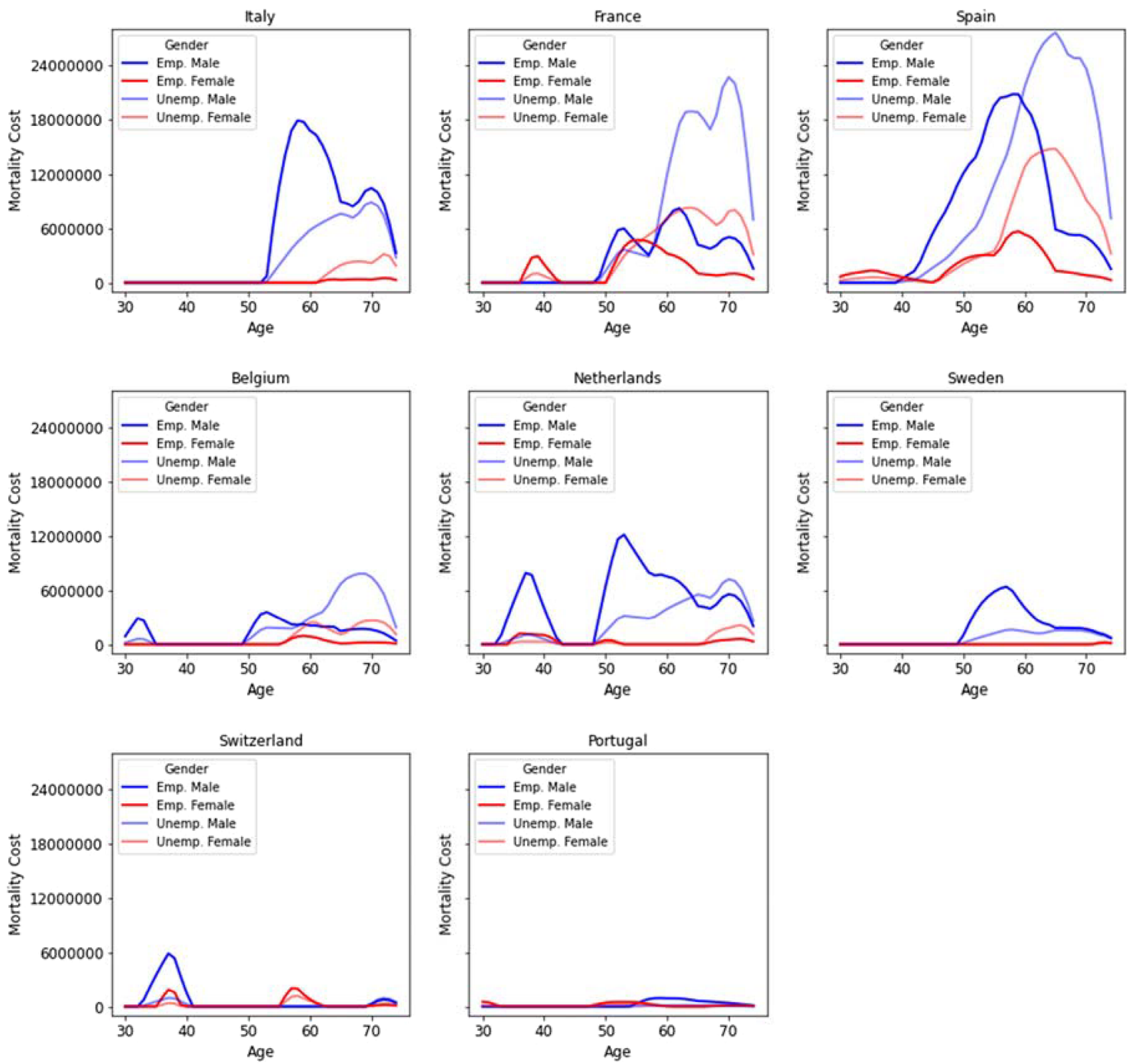

Key: Emp. Male - Employed males

Emp. Female - Employed females

Unemp. Male - non-employed males

Unemp. Female - non-employed females

Fig. 1 Paid and unpaid premature mortality costs $(€ 2020)$ due to excess mortality by country, gender and age following initial country outbreak* to 22nd May 2020

\section{Discussion}

There is a requirement to balance the public health need to control COVID-19 transmission and minimise cases and deaths with the wider needs of society and the economy. Welfare economics provides a framework within which to assess allocative efficiency concerns over time relating to efficiency/equity trade-offs [21]. To undertake this, a range of metrics are necessary to inform policy makers' decisions, and these include wider concepts of the COVID-19 burden with an associated monetary value that is standardised and can be compared to other diseases [6]. While costs are 
Table 3 Paid and unpaid premature mortality costs per death (€2020) due to excess mortality by country and by gender following initial country outbreak to 22nd May 2020

\begin{tabular}{|c|c|c|c|c|c|c|c|c|c|c|c|c|}
\hline \multirow[t]{3}{*}{ Region/country } & \multicolumn{8}{|c|}{ Employed individuals } & \multirow{2}{*}{\multicolumn{4}{|c|}{$\frac{\text { Non-employed individuals }}{\text { Unpaid production losT }}$}} \\
\hline & \multicolumn{4}{|c|}{ Paid production lost } & \multicolumn{4}{|c|}{ Unpaid production lost } & & & & \\
\hline & Males & Females & Total & Rank & Males & Females & Total & Rank & Males & Females & Total & Rank \\
\hline Belgium & 61,897 & 18,914 & 51,228 & 6 & 13,614 & 7,978 & 12,215 & 4 & 129,553 & 133,515 & 130,536 & 2 \\
\hline France & 40,825 & 39,470 & 40,382 & 8 & 8,458 & 15,836 & 10,869 & 5 & 119,462 & 121,679 & 120,186 & 3 \\
\hline Germany $^{\mathrm{a}}$ & - & - & - & - & - & - & - & - & - & - & - & - \\
\hline Italy & 57,584 & 7,876 & 52,385 & 5 & 6,615 & 2,904 & 6,226 & 8 & 32,844 & 60,924 & 35,781 & 7 \\
\hline The Netherlands & 161,291 & 38,229 & 138,562 & 3 & 35,124 & 11,781 & 30,812 & 3 & 103,506 & 62,028 & 95,845 & 4 \\
\hline Portugal & 58,015 & 51,472 & 56,013 & 4 & 4,260 & 20,829 & 9,329 & 7 & 10,024 & 41,272 & 19,584 & 8 \\
\hline Spain & 52,937 & 29,501 & 46,633 & 7 & 9,561 & 11,703 & 10,137 & 6 & 82,289 & 110,955 & 90,000 & 5 \\
\hline Sweden & 156,899 & 11,337 & 147,634 & 2 & 44,428 & 4,536 & 41,889 & 2 & 79,393 & 26,899 & 76,052 & 6 \\
\hline Switzerland & 426,831 & 241,452 & 350,325 & 1 & 109,905 & 93,538 & 103,151 & 1 & 138,800 & 175,315 & 153,869 & 1 \\
\hline $\begin{array}{l}\text { Average (for } 8 \\
\text { European coun- } \\
\text { tries) }\end{array}$ & 137,789 & 63,237 & 119,451 & & 30,356 & 23,745 & 29,669 & & 109,083 & 97,297 & 107,517 & \\
\hline \multirow{3}{*}{\multicolumn{3}{|c|}{ Region/country }} & \multicolumn{10}{|c|}{ Employed + non-employed individuals } \\
\hline & & & \multicolumn{10}{|c|}{ Total production } \\
\hline & & & \multicolumn{3}{|l|}{ Males } & \multicolumn{3}{|l|}{ Females } & \multicolumn{3}{|l|}{ Total } & Rank \\
\hline Belgium & & & \multicolumn{3}{|l|}{68,355} & \multicolumn{3}{|l|}{53,469} & \multicolumn{3}{|l|}{64,660} & 4 \\
\hline France & & & \multicolumn{3}{|l|}{56,248} & \multicolumn{3}{|l|}{58,995} & \multicolumn{3}{|l|}{57,146} & 5 \\
\hline Germany & & & \multicolumn{3}{|l|}{-} & \multicolumn{3}{|l|}{-} & \multicolumn{3}{|l|}{-} & - \\
\hline Italy & & & \multicolumn{3}{|l|}{32,348} & \multicolumn{3}{|l|}{23,901} & \multicolumn{3}{|l|}{31,464} & 7 \\
\hline The Netherlands & & & \multicolumn{3}{|l|}{99,973} & \multicolumn{3}{|l|}{37,346} & \multicolumn{3}{|l|}{88,407} & 3 \\
\hline Portugal & & & \multicolumn{3}{|l|}{24,099} & \multicolumn{3}{|l|}{37,858} & \multicolumn{3}{|l|}{28,309} & 8 \\
\hline Spain & & & \multicolumn{3}{|l|}{48,262} & 50,719 & & & 48,923 & & & 6 \\
\hline Sweden & & & 93,573 & & & 14,257 & & & 88,525 & & & 2 \\
\hline Switzerland & & & 225,179 & & & 170,102 & & & 202,448 & & & 1 \\
\hline Average (for 8 Eur & pean coun & ries) & 92,409 & & & 61,426 & & & 85,546 & & & \\
\hline
\end{tabular}

The starting point for each country varied and was defined as the week in which the cumulative total of COVID-19-related deaths reached 10 in that country

${ }^{a}$ No evidence of excess deaths recorded compared to the previous 5 years in Germany over the 30-74 age group

Fig. 2 Paid and unpaid premature mortality costs due to excess mortality compared to Quarter 2 Gross Domestic Product (GDP) (\%) by country for 2019

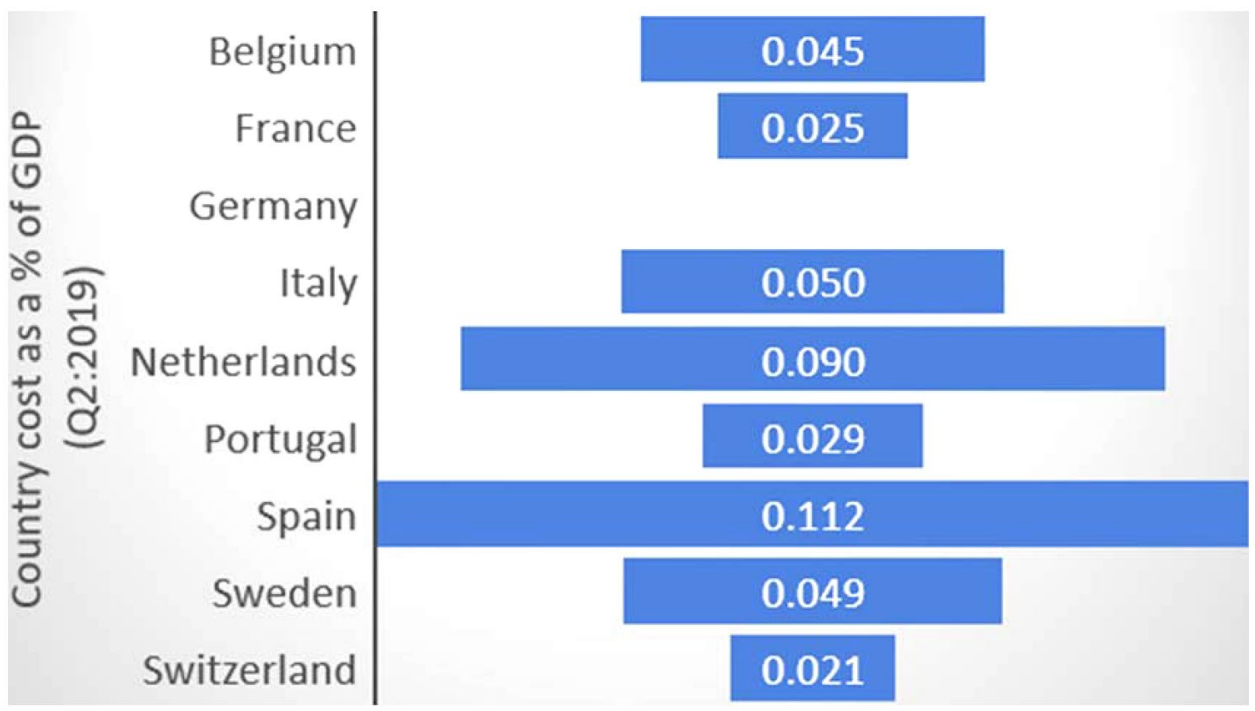


incurred now by Governments tackling the pandemic, the benefits are spread out over many years. Our estimates of premature mortality costs across Europe provide a complementary perspective for policymakers and help to inform the debate over appropriate government resource allocation at the expense of other routine health activities and widespread disruption of the economy. In particular, our estimates complement those published by the Office for National Statistics on all-cause mortality patterns of selected European countries [10].

\section{COVID-19 comparative burden across Europe}

Our estimates of productivity costs associated with excess premature mortality during the first phase of the COVID19 outbreak across nine European countries ranged from $€ 0.015$ billion in Portugal to $€ 0.35$ billion in Spain (paid productivity costs), and from $€ 0.023$ billion in Portugal to $€ 1.1$ billion in Spain (paid and unpaid productivity costs). Spain experienced the greatest economic burden from the initial phase of the pandemic ranking highest for not only number of deaths (as has been reported elsewhere) [10], but also for YPPLL, premature mortality costs (paid and unpaid) and costs compared to GDP.

Moreover, our estimates revealed varied findings as we altered the lens of analysis. For example, France, ranked third in terms of total deaths, YPPLL, and second for premature mortality costs, fell to the lowest ranked country (eighth) in terms of cost per death (paid) and second lowest for premature mortality costs as a percentage of GDP. In contrast, Switzerland changed from lowest burden for deaths per 100,000 of the population to highest for premature mortality costs per death. This change in ranking is primarily due to combining the epidemiological data and the economic data to produce cost estimates of premature mortality. Switzerland's national gross wage and employment rate are in excess of many other European countries, and therefore, the comparative monetary burden of COVID-19 for Switzerland is in excess of the pure public health burden as measured by mortality and years of life lost.

The premature mortality costs for COVID-19 are considerable compared to the economic burden of other diseases in Europe over a similar time frame. For example, our premature mortality cost estimate for Spain over a 9-week period during the first phase of COVID-19 infections was $€ 0.35$ billion which extrapolates to an annual figure of $€ 2$ billion or $0.18 \%$ of 2020 GDP. Over an equivalent timeframe in Spain, all-cause mortality accounted for $€ 10$ billion in productivity costs in 2020 (value inflated from original 2009 figure according to Spanish CPI data from 2009 to 2020) or 0.89\% of GDP [22]. The COVID-19 premature mortality burden would be 1.5 times larger than the burden of all circulatory system disease-related premature mortality costs in Spain in
2020 ( $€ 1.4$ billion) and almost $70 \%$ of the cost of cancer in Spain in 2020 ( $€ 3.0$ billion).

Similarly, across Europe, our estimated premature mortality costs for COVID-19 were comparable to cardiovascular disease which is ranked highest for all-cause mortality in the region. For example, COVID-19 premature mortality costs were $€ 0.19$ billion over a 9-week period [or $€ 1.1$ billion extrapolated annual figure (0.14\% of GDP)] for The Netherlands. Premature mortality costs for cardiovascular disease were estimated at $€ 1.3$ billion in The Netherlands $(0.19 \%$ of GDP) in 2015 [23].

Fewer comparable estimates are available for communicable diseases. Estimates of the economic burden of influenza in the US revealed a per death cost for premature mortality of $\$ 114,470$ in 2015 which is close to our average $€ 137,789$ per excess COVID-19-associated death across Europe [24]. This tentatively suggests that the cost per death is similar for COVID-19 and seasonal influenza, with the total burden dependent on the number of excess deaths. Comparative cost per death estimates in Europe for cancer for example is $€ 219,241$ [25] which equate to almost 1.6 times the size of COVID-19 estimates.

Our findings provide insight into the significant challenge posed by the outbreak of the COVID-19 pandemic across Europe and the economic impact of uncontained community spread infections in terms of premature mortality in the initial phase of the infection. We reveal how this can translate from a major public health burden to an economic one as well, and how the economic lens transforms and changes how the burden is experienced by individual countries depending on the underlying age profile of premature deaths, and the extant country-specific economic and labour characteristics.

\section{COVID-19 gender and age burden}

Our results revealed that the premature mortality cost burden in the productive population (assumed 30-74 years of age) is heaviest in the male population. This is the case across a range of metrics including deaths, where the male/female ratio ranged between 1.42 in Switzerland to 14.71 in Sweden, and our economic estimates where premature mortality costs in the employed population was between 2.13 (France) and 203.59 (Sweden) more burdensome in males. This contrasts with non-communicable diseases such as cardiovascular disease where the male/female premature mortality cost ratio was 1.21 in France and 1.15 in Sweden and for cancer (2.01 for France and 1.06 for Sweden) [26, 27]. In particular, our estimates revealed that amongst the employed, male premature mortality costs represented almost $87 \%$ (or $€ 0.93$ billion) of the total productivity costs. This finding is driven by male costs tending to be highest in the 55-64 age group, or younger, where individuals earn higher wages and have 
the potential to generate more years of life lost compared to older age groups. This is in contrast to female costs which are highest in the 65-74 age group across two of the countries studied (Italy and Sweden). This percentage of the burden apportioned to males was reduced somewhat when we aggregated paid and unpaid productivity costs together in a more appropriate societal measure of work lost (76\%); however, they still remained dominant in our total aggregated premature mortality cost measure.

\section{Economic burden and COVID-19 public health measures}

Containing and mitigating the spread of COVID-19 and reducing the number and severity of waves of infection are necessary to enable effective management and treatment of cases. At the time of writing, Europe is enduring a third serious wave of COVID-19 infections, hospitalisations and deaths [28]. A shortage of vaccines is hindering progress. Controlling further phases of outbreaks and an associated surge in the demand for diagnostic and treatment services through the implementation of vaccination programmes will entail obvious public health benefits in the form of avoidable mortality. Our results show that there are considerable economic benefits to an efficient and wide-ranging public health response in terms of minimising excess deaths and associated premature mortality costs.

We would note that in spite of their magnitude, our costs are a lower bound of the economic costs of COVID-19. A broad spectrum of productivity costs are arising due to infection (or exposure to someone who was infected) with an associated need to self-isolate and, in many cases, not go to work [29]. Evidence is also emerging of longer-term "post-viral" health consequences which may impact on the productivity of populations [30]. While not accounting for the entirety of potential productivity costs associated with COVID-19 due to their emerging nature, our results nevertheless show the considerable economic benefits that could be accrued from appropriate public health measures.

Our premature mortality cost estimates revealed that Italy and Spain were the most burdened European countries in the first phase of COVID-19 infections. While a comparatively low capacity in their healthcare systems [31] may have impeded their response to COVID-19, these two countries were the first in Europe to experience the uncontrolled outbreak of COVID-19 infections. Governments in both cases were taken by surprise and the respective populations were not sufficiently alarmed to adjust their social behaviour to the risks of becoming infected [32]. Hence, for example, Italy witnessed compliance issues with initial restrictions and had limited time to prepare contact tracing and appropriate testing [33].
On average across Europe, the initial section of the exponential curve of the first wave of COVID-19 infections was flatter in countries that were affected later [32] and this is indicated in our premature mortality cost results. This latecomer advantage, where the virus was already expected, allowed countries such as Germany to harness peoples' changing behaviour and their voluntarily decision to implement social distancing measures, supported by earlier official decisions in relation to lockdown. Measures taken in Germany (widespread testing, rapid results, contract tracing and early border closure) [30], against the background of a well-financed and resourced healthcare system [31], managed to mitigate the worst effects of the first phase of the pandemic as evidenced by our results which indicate no discernible excess deaths, and hence limited premature mortality costs, in the 30-74 age group.

Interestingly, Sweden emerged as the fourth most heavily burdened country compared to GDP in our study. Sweden, unlike other European countries, opted for a no-lockdown approach which entailed keeping the economy open and not closing schools for those under 16 [34]. Such a light touch approach may benefit the wider economy in terms of economic growth, but our premature mortality cost estimates highlight the complex trade-offs that policy makers must contend with during a time of uncertainty.

\section{Impact on labour market, labour and economic growth}

COVID-19 has implications for European labour markets and economic growth. The size and quality of a county's labour force and its economic growth are intrinsically linked. While the virus disproportionately impacts older age groups, we have shown in the cases of Spain $(61,106)$, France $(24,303)$, and in Italian males in particular $(24,452)$, considerable excess mortality in age cohorts participating in the labour force which has led to substantial YPPLL over the relatively short time frame covered. For example, if we examine an age cohort of the labour force in which the vast majority of premature COVID-19-related deaths occurred in our study - those aged above 55-we find between $0.01 \%$ (Switzerland) and $0.20 \%$ (Spain) of those active in this age cohort died due to COVID-19-related premature mortality. The negative impact on European labour markets has increased further with successive waves of infection.

\section{Strengths and limitations}

Our results provide insight into the potential effectiveness, or otherwise, of public health strategies implemented across Europe including restrictions on population movement and activities. The cost estimates also contribute to the raw material for appropriate and effective Health Technology 
assessment frameworks applied to COVID-19 therapies. We produce standardised costs that can be compared with other diseases to inform future resource allocation decisions amongst public health decision makers.

Our study employed YPPLL as a standard comparator of the disease burden and modified this for 75 years of age upper threshold following previous OECD recommendations [35]; this also accords with our societal perspective for the analysis including unpaid costs and increasing average life expectancies across Europe. Going beyond the traditional retirement age in Europe (65) may have hindered the quality of the economic data used in the analysis. In addition, although all-cause excess mortality can be a good proxy for the effect of COVID-19, due to the absence of other major public health events across Europe during the study timeframe [36], there are caveats to its use.

\section{Conclusion}

Our study shows that COVID-19-related premature mortality costs are significant across Europe. Our results provide a valuable alternative, and novel, perspective on the burden of the virus, over and above traditional public health measures. Importantly, the findings highlight economic savings that may be accrued by applying timely public health measures.

Supplementary Information The online version contains supplementary material available at https://doi.org/10.1007/s10198-021-01351-8.

Funding None.

\section{References}

1. International Monetary Fund: World Economic Outlook Update (2020). https://www.imf.org/en/Publications/WEO/Issues/2020/ 06/24/WEOUpdateJune2020. Accessed 5 Jul 2020

2. World Bank: Global Economic Prospects (2020). https://openk nowledge.worldbank.org/handle/10986/33748. Accessed 1 Jul 2020

3. European Centre for Disease Prevention and Control: COVID-19 situation update for the EU/EEA and the UK European, as of 9 August 2020 (2020). https://www.ecdc.europa.eu/en/cases-2019ncov-eueea. Accessed 9 Aug 2020

4. Hanlon, P., Chadwick, F., Shah, A., et al.: COVID-19—exploring the implications of long-term condition type and extent of multimorbidity on years of life lost: a modelling study [version 1; peer review: awaiting peer review]. Wellcome Open Res. 5, 75 (2020). https://doi.org/10.12688/wellcomeopenres.15849.1

5. Emanuel, E.J., Persad, G., Upshur, R., et al.: Fair allocation of scarce medical resources in the time of COVID-19. N. Engl. J. Med. 382(21), 2049-2055 (2020). https://doi.org/10.1056/NEJMs b2005114

6. Miles, D., Stedman, M., Heald, A.: Living with Covid-19: balancing costs against benefits in the face of the virus. Natl. Inst. Econ. Rev. 253, R60-R76 (2020). https://doi.org/10.1017/nie.2020.30
7. Bartsch, S.M., Ferguson, M.C., McKinnell, J.A., et al.: The potential health care costs and resource use associated with COVID19 in the United States. Health Aff. (Millwood) 39(6), 927-935 (2020). https://doi.org/10.1377/hlthaff.2020.00426

8. Krol, M., Brouwer, W., Rutten, F.: Productivity costs in economic evaluations: past, present, future. Pharmacoeconomics 31(7), 537-549 (2013). https://doi.org/10.1007/s40273-013-0056-3

9. Hanly, P., Pearce, A., Sharp, L.: The cost of premature cancerrelated mortality: a review and assessment of the evidence. Expert Rev. Pharmacoecon. Outcomes Res. 14(3), 355-377 (2014). https://doi.org/10.1586/14737167.2014.909287

10. Office for National Statistics (UK): Comparisons of all-cause mortality between European countries and regions: January to June 2020 (2020). https://www.ons.gov.uk/peoplepopulationandc ommunity/birthsdeathsandmarriages/deaths/articles/comparison sofallcausemortalitybetweeneuropeancountriesandregions/janua rytojune2020 Accessed 10 Jul 2020

11. Grossman, M.: On the concept of health capital and the demand for health. J. Polit. Econ. 80(2), 223-255 (1972)

12. Eurostat: Weekly deaths-special data collection (2020). https:// ec.europa.eu/eurostat/cache/metadata/en/demomwk_esms.htm. Accessed 20 Jun 2020

13. Statistisches Bundesamt: Deaths-number of cases by days, weeks, months, age groups and federal states for Germany 2016-2020. August 7, 2020 (2020). https://www.destatis.de/DE/ Themen/Gesellschaft-Umwelt/Bevoelkerung/Sterbefaelle-Leben serwartung/Tabellen/sonderauswertung-sterbefaelle.html?nn= 23768. Accessed 10 Aug 2020

14. Eurostat: Mean annual earnings by sex, age and occupation. 10 employees or more (2014). https://ec.europa.eu/eurostat/web/ labour-market/earnings/database Accessed 4 Aug 2020.

15. Eurostat: Harmonized Index of Consumer Price-inflation rate: Annual average rate of change (2019c). https://ec.europa.eu/euros tat/databrowser/product/page/TEC00118. Accessed 4 Aug 2020

16. Eurostat: Unemployment rates by sex, age and country of birth (\%) (2018). https://ec.europa.eu/eurostat/web/lfs/data/database Accessed 1 Aug 2020

17. Eurostat: Harmonised European Time Use Surveys (HETUS) Overview (2020). https://ec.europa.eu/eurostat/web/time-usesurveys. Accessed $25 \mathrm{Jul} 2020$

18. International Labour Organisation: International Standard Classification of Occupations (ISCO) (2008). https://ilostat.ilo.org/resou rces/methods/classification-occupation/. Accessed 26 Jul 2020

19. Weisbrod, B.A.: The Valuation of human capital. J. Polit. Econ. 69(5), 425-436 (1961)

20. Claxton, K., Sculpher, M., Culyer, A., et al.: Discounting and cost-effectiveness in NICE - stepping back to sort out a confusion. Health Econ 15(1), 1-4 (2006). https://doi.org/10.1002/hec.1081

21. Chilton, S., Nielsen, J.S., Wildman, J.: Beyond COVID-19: How the 'dismal science' can prepare us for the future. Health Econ. 29(8), 851-853 (2020). https://doi.org/10.1002/hec.4114 (Epub ahead of print)

22. Peña Longobardo, L.M., Aranda-Reneo, I., Oliva Moreno, J., Vall Castello, J.: Pérdidas laborales ocasionadas por muertes prematuras en España: un análisis para el periodo 2005-2009 [Change in productivity losses due to premature deaths in Spain: 2005-2009]. Rev. Esp. Salud Publica 89(1), 39-50 (2015). https://doi.org/10. 4321/S1135-57272015000100005

23. Wilkins, E., Wilson, L., Wickramasinghe, K., Bhatnagar, P., Leal, J., Luengo-Fernandez, R., Burns, R., Rayner, M., Townsend, N.: European Cardiovascular Disease Statistics 2017. European Heart Network, Brussels. https://www.bhf.org.uk/informationsupport/ publications/statistics/european-cardiovascular-disease-statistics2017 Accessed 25 Jul 2020

24. Putri, W.C.W.S., Muscatello, D.J., Stockwell, M.S., Newall, A.T.: Economic burden of seasonal influenza in the United States. 
Vaccine 36(27), 3960-3966 (2018). https://doi.org/10.1016/j. vaccine.2018.05.057

25. Hanly, P., Soerjomataram, I., Sharp, L.: Measuring the societal burden of cancer: the cost of lost productivity due to premature cancer-related mortality. Eur. Int. J. Cancer 136(4), E136-E145 (2015), https://doi.org/10.1002/ijc.29105

26. Leal, J., Luengo-Fernández, R., Gray, A., Petersen, S., Rayner, M.: Economic burden of cardiovascular diseases in the enlarged European Union. Eur. Heart J. 27(13), 1610-1619 (2006). https:// doi.org/10.1093/eurheartj/ehi733

27. Luengo-Fernandez, R., Leal, J., Gray, A., Sullivan, R.: Economic burden of cancer across the European Union: a population-based cost analysis. Lancet Oncol. 14(12), 1165-1174 (2013). https:// doi.org/10.1016/S1470-2045(13)70442-X

28. COVID-19: Building a stronger Europe. Lancet 397(10280), 1157 (2021). https://doi.org/10.1016/S0140-6736(21)00720-0

29. UN/ILO: Policy Brief: The World of Work and COVID-19. June 2020 (2020). https://www.un.org/sites/un2.un.org/files/sg_policy_brief_covid_world_of_work_and_covid-19_june_2020.pdf Accessed 10 July 2020

30. Ellul, M.A., Benjamin, L., Singh, B., Lant, S., Michael, B.D., Easton, A., Kneen, R., Defres, S., Sejvar, J., Solomon, T.: Neurological associations of COVID-19. Lancet Neurol. 19(9), 767-783 (2020)

31. Organisation for Economic Co-operation and Development (OECD): Beyond containment: health systems responses to COVID 19 in the OECD. April 16, 2020 (2020). https:// www.oecd.org/coronavirus/policy-responses/beyond-conta inment-health-systems-responses-to-covid-19-in-the-oecd-6ab74 0c0/ Accessed 13 Jun 2020

32. Plümper, T., Neumayer, E.: Lockdown policies and the dynamics of the first wave of the Sars-CoV-2 pandemic in Europe. J. Eur. Public Policy (2020). https://doi.org/10.1080/13501763.2020. 1847170

33. Boccia, S., Ricciardi, W., Ioannidis, J.P.A.: What other countries can learn from Italy during the COVID-19 Pandemic. JAMA Intern Med. 180(7), 927-928 (2020). https://doi.org/10.1001/ jamainternmed.2020.1447

34. Habib, H.: Has Sweden's controversial covid-19 strategy been successful? BMJ 369, m2376 (2020)

35. Mitra, A.K., Payton, M., Kabir, N., Whitehead, A., Ragland, K.N., Brown, A.: Potential years of life lost due to COVID-19 in the United States, Italy, and Germany: an old formula with newer ideas. Int J Environ Res Public Health. 17(12), 4392 (2020). https://doi.org/10.3390/ijerph17124392

36. Vestergaard, L.S., Nielsen, J., Richter, L., et al.: Excess all-cause mortality during the COVID-19 pandemic in Europe-preliminary pooled estimates from the EuroMOMO network, March to April 2020. Euro Surveill. (2020). https://doi.org/10.2807/15607917.ES.2020.25.26.2001214

Publisher's Note Springer Nature remains neutral with regard to jurisdictional claims in published maps and institutional affiliations. 